\title{
Oceanography
}

CITATION

Rogers, W.E., J.D. Dykes, and P.A. Wittmann. 2014. US Navy global and regional wave modeling. Oceanography 27(3):56-67, http://dx.doi.org/10.5670/oceanog.2014.68.

DOI

http://dx.doi.org/10.5670/oceanog.2014.68

COPYRIGHT

This article has been published in Oceanography, Volume 27, Number 3, a quarterly journal of The Oceanography Society. Copyright 2014 by The Oceanography Society. All rights reserved.

USAGE

Permission is granted to copy this article for use in teaching and research. Republication, systematic reproduction, or collective redistribution of any portion of this article by photocopy machine, reposting, or other means is permitted only with the approval of The Oceanography Society. Send all correspondence to: info@tos.org or The Oceanography Society, PO Box 1931, Rockville, MD 20849-1931, USA. 


\section{US Navy Global and \\ Regional Wave Modeling}

BY W. ERICK ROGERS, JAMES D. DYKES, AND PAUL A. WITTMANN

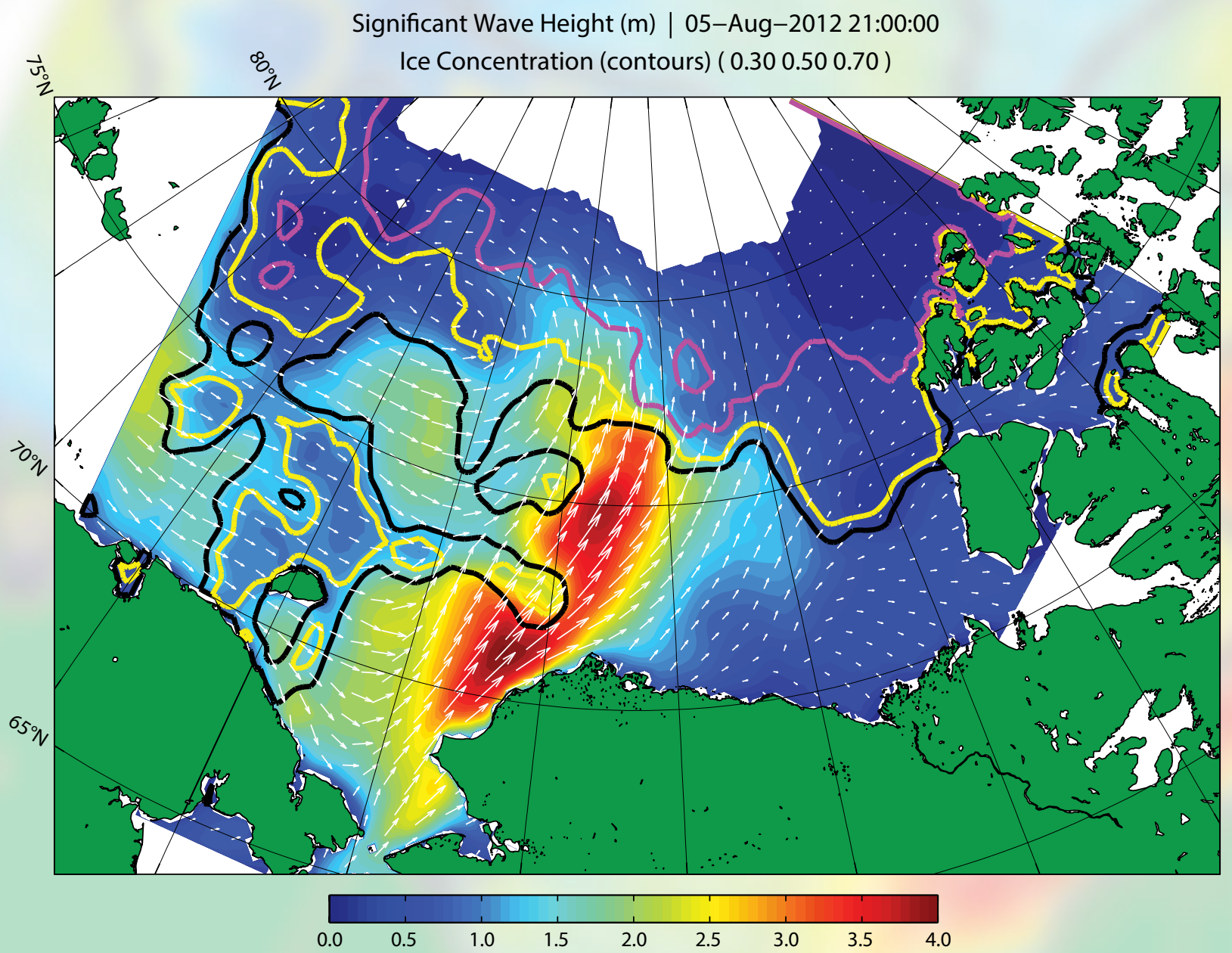

Significant waveheight $(\mathrm{m})$ (colors) and mean direction (arrows) from a Beaufort and Chukchi Seas regional wave model hindcast with WAVEWATCH III (R) during the "Great Arctic Cyclone" of 2012 (2100 UTC August 5, 2012, shown here). Contours indicate ice concentration fraction of $0.3,0.5$, and 0.7 , from an operational analysis based on satellite radiometer. 
ABSTRACT. This article reviews the prediction of wind-generated surface gravity waves over the world ocean by the US Navy. The numerical wave model WAVEWATCH III ${ }^{\circ}$ is used operationally for this purpose at the two primary Navy operational centers, the Fleet Numerical Meteorology and Oceanography Center and the Naval Oceanographic Office. This model is briefly described, and an overview is given of the current operational and near-operational features of global- and regionalscale wave models at the two centers. Planned features are summarized.

\section{INTRODUCTION}

Particular attention is given in this article to progress made since an earlier paper of similar theme by Jensen et al. (2002). For a more detailed review of progress prior to 2002, the reader is referred to this earlier paper.

Prior to the Second World War, generation of routine meteorological forecasts for the US military was well underway, with services provided first by the US Army Signal Corps and later by the Army Air Corps Weather Service. At sea, because of the obvious close link between wind and wind-generated seas, these services provided some limited, implicit wave forecasts. For example, a severe winter storm over any significant body of water can reliably be expected to generate large and potentially dangerous waves. However, this linkage is limited because it does not account for important variables that determine wave magnitude both within the storm and at distant locations. The most important of these variables is associated with

(1) the temporal and spatial variability of the wind field and the basin geometry, which determine the fetch and duration available for generation of wave energy, and (2) the direction and distance of propagation once the waves leave the active generation area. Some information climatology for certain regions, but no wave forecasts were produced.

During the war, the need for wave forecasts was recognized, and action was taken by separate, parallel efforts of the American and British war departments. The most pressing problem was the determination of operability of landing craft within the surf; two-meter breakers were considered likely to cause broaching and sinking (AIP, 1986; Munk and Day, 2002). The US job was given to two scientists from Scripps Institution of Oceanography, Harold Sverdrup and Walter Munk, who developed their initial methods working at the Pentagon in September and October 1942 (Munk and Day, 2002). These methods were applied to Operation Torch, the British-American landing of November 8, 1942, on the Atlantic and Mediterranean coasts of Northwest Africa. The methods were subsequently was compiled by the military on wave refined by the two researchers after they returned to Scripps in February 1943, and they were taught to officers of the military services, at which time wave forecasting was formally introduced to the US Navy. The methods were applied for the Normandy invasion of June 1944 and a number of other invasions in the Pacific and Mediterranean. It is impossible to estimate the number of lives saved with these forecasts, but it is reasonably assumed to be in the thousands over the course of the war (Kinsman, 1984).

The methods of Sverdrup and Munk, summarized in Kinsman (1984), were by necessity quite crude, requiring, for example, a forecaster to quantify a single fetch and duration associated with a single wind speed, though winds over the real ocean are non-stationary and non-uniform. Individual forecasts were made using a sequence of charts and nomographs. These simple concepts continued to be used into the era of electronic computing.

In their review of wave modeling at the National Weather Service (NWS), Tolman et al. (2002) state that the first computer-generated wave forecasts for the NWS were made in July 1956, as described by Hubert (1957). The NWS at the time was known as the Weather Bureau, and Hubert was, in fact, a Navy officer detailed to the Joint Numerical Weather Prediction Unit, a joint project by the US Air Force, Navy, and Weather Bureau. These initial computer 
forecasts were more primitive than the earlier methods of Sverdrup and Munk, representing a step backward of sorts, because they assumed infinite fetch, disregarded swell, and were only beginning to introduce the concept of limited duration. By the mid 1960s, these models had been improved to include simplified swell predictions, and were implemented at the Fleet Numerical Oceanography Center (FNOC; Clancy et al., 1986; Wittmann and Clancy, 1993). By the mid 1970s, FNOC was running its first spectral model, SOWM (Spectral Ocean Wave Model), based on observational and theoretical work of W.J. Pierson and others (Clancy et al., 1986). It was a regional model, subsequently replaced by a global version (GSOWM) in the mid-1980s (Clancy et al., 1986). Implementation of the first modern (so-called "third generation") wave model, WAM (WAve Model; WAMDI Group, 1988), occurred in the 1990s, with a regional implementation at FNOC in 1990 and a global implementation in 1994 (Wittmann and Clancy, 1993, 2004; Wittmann et al., 1995). By that time, the operational center was known by its current name, Fleet Numerical Meteorology and Oceanography Center (FNMOC).

During this progression of Navy wave models, the most important breakthrough was arguably the development of the conservation equation for spectral density, sometimes known as

W. Erick Rogers (erick.rogers@nrlssc.navy. mil) is Oceanographer, Naval Research Laboratory, Stennis Space Center, MS, USA. James D. Dykes is Physical Scientist, Naval Research Laboratory, Stennis Space Center, MS, USA. Paul A. Wittmann is Oceanographer, Fleet Numerical Meteorology and Oceanography Center, Monterey, CA, USA. the "radiative transfer equation" for wave energy. This was first expressed by Gelci et al. (1956) and Hasselmann (1960). Written in the Cartesian coordinates, the equation is

$$
\begin{gathered}
\frac{\partial N}{\partial t}+\frac{\partial C_{x} N}{\partial x}+\frac{\partial C_{y} N}{\partial y} \\
+\frac{\partial C_{\sigma} N}{\partial \sigma}+\frac{\partial C_{\theta} N}{\partial \theta}=\frac{S}{\sigma}
\end{gathered}
$$

The prognostic variable is the wave action density $N$, equal to energy density divided by angular relative frequency $(N=E / \sigma)$, which is a function of space and time, $N=N(x, y, \theta, \sigma, t)$. Relative frequency $\sigma$ is the wave frequency measured from a frame of reference moving with a current, if a current exists; $\theta$ is wave direction; $C$ is the wave action propagation speed in $(x, y, \theta, \sigma)$ space. In the absence of currents, $C_{x}$ is the $x$-component of the group velocity $C_{g}$. The right-hand side of the governing equation is the total of source/sink terms expressed as rate of change of wave action density, where $S=S(x, y, \theta, \sigma, t)$ is most generally represented by three terms, $S=S_{\text {in }}+S_{n l}+S_{d s}$ : input by wind, nonlinear interactions, and dissipation, respectively.

With the introduction of Equation 1, the sequence of charts and nomographs for manual forecasting were replaced with a single integration. Fetch and duration are not calculated, but are implicit features of the integration. Refraction by bathymetry and currents are included via $C_{\sigma}$ and $C_{\theta}$, and shoaling effects are included via the $\partial / \partial x$ and $\partial / \partial y$ terms. In the case of spherical coordinates, the advection terms are modified to account for Earth's curvature (see WAMDI Group, 1988). Diffraction is customarily disregarded at these scales.

In first generation wave models such as SOWM, the right-hand side of
Equation 1 was highly parameterized into a pair of source functions; one represented growth as relaxation toward a fully developed sea state, and the other was an ad hoc mechanism for dissipation of swell. In today's third-generation wave models, the three fundamental source terms are treated separately without artificial constructs to recreate a desired spectral shape, and there are multiple subtypes for source terms, especially $S_{d s}$, because dissipation can occur for many reasons. The primary dissipation in deep water is by whitecapping (breaking), but other mechanisms become important in specific situations, for example, interactions with sea ice, bedforms, mud, or turbulence in the water. During the last 30 years, the heavy-handed empiricisms of models like SOWM have gradually been replaced with source functions based on physics. However, with few exceptions, source terms still include some empirical coefficients, required by limitations on current theory and observational capabilities, simplifying assumptions (e.g., linear wave theory, linear superposition of sinusoids, local homogeneity), and generally chaotic nature of the real ocean.

A particular feature of Equation 1 is worth emphasizing: the models used for global and regional wave forecasts are phase-averaged, because phase-resolving models of short wind-waves would require spatial resolution of $\mathrm{O}(1 \mathrm{~m})$. Individual waves are not resolved, but the sea state is instead treated using spectra. At any given time and location, a wave spectrum identifies the level of energy present in discrete computational bins that are typically organized by frequency (or wavenumber) and direction of propagation. The relevant conserved quantity for the case without currents is wave energy spectral density $E(\sigma, \theta)$, 
and for the more general case with or without currents, it is wave action spectral density $N(\sigma, \theta)$. Phase-resolving wave models are not presently used by the operational Navy for forecasting at any scale, though in principle, it is feasible at smaller scales, particularly if local wave generation and shorter wind sea frequencies are excluded (e.g., see O’Reilly and Guza, 1993).

Large-scale wave models have a number of applications operationally, such as for the historical example of an amphibious assault given above. However, large-scale models are rarely used directly for such applications because the spatial resolution is insufficient to represent nearshore bathymetry. Instead, the large-scale wave model is used to create boundary forcing for a telescoping sequence of coastal models. At each step, the resolution is typically increased (improved) by a factor of four to eight. Boundary forcing consists of directional wave spectra prescribed at intervals along the boundaries. Nearshore forecasts are important not only for the initial assault, to check against operating thresholds of medium and small craft, but also for so-called "logistics over the shore," that is, the movement of men and matériel in the subsequent days. In fact, the latter sort of operations is more likely to be restricted by surf conditions (Su and Vincent, 1996). Nearshore forecasts are also utilized for Special Operations in the littoral.

Offshore, the large-scale models are used more directly, for example, in ship routing and high seas warnings. While the most severe storms can generally be avoided by ships using meteorological forecasts, a wave model is needed to anticipate the swells emanating from these storms. Certain operations, such as ship-to-ship transfer of matériel can be particularly sensitive to long swells, making such forecasts useful for planning. Wave conditions can affect the cost of ship movement. Specific variables pertinent to seakeeping are further discussed below in the context of near-operational products.

Other uses for wave forecasts have been proposed but are not operational at the time of writing. Ambient noise is important to undersea warfare; wave forecasts can assist in noise predictions because, along with ship traffic, wave breaking is a primary source of ambient noise. The wave-induced drift current, sometimes called "Stokes drift," is readily calculated from directional spectra, and is critical for prediction of drift trajectory (e.g., for search and rescue or debris recovery). Waves also play an important role in the dispersion and advection of oil spills. inform subsequent model development efforts. For example, it is useful to know if error is dominated by model forcing vs. errors in the model itself, and if the latter, whether it is in the model physics or numerics. Detailed discussion of this topic is beyond the scope of this paper, but interested readers can find many papers on the topic, for example, Rogers et al. (2005), Cavaleri et al. (2007), and Durrant et al. (2013).

WAVEWATCH III: KEY FEATURES AND CODE DEVELOPMENT

The WAVEWATCH model was originally developed at Delft University (Tolman, 1991), and its current form, referred to as WAVEWATCH III ${ }^{\oplus}$ (WW3), was developed at the National Oceanic and Atmospheric Administration's National Centers for Environmental Prediction (NOAA NCEP; Tolman et al., 2002).

\section{S OFFSHORE, THE LARGE-SCALE MODELS ARE USED MORE DIRECTLY, FOR EXAMPLE, IN SHIP ROUTING AND HIGH SEAS WARNINGS. WHILE THE MOST SEVERE STORMS CAN GENERALLY BE AVOIDED BY SHIPS USING METEOROLOGICAL FORECASTS, A WAVE MODEL IS NEEDED TO ANTICIPATE THE SWELLS EMANATING FROM THESE STORMS.}

Wave models are, of course, subject to errors. Validation and analysis of sources of errors in hindcasts and operational predictions are a major component of work performed by The Naval Research Laboratory's (NRL's) Oceanography Division. Results from these studies
WW3 is free and open source, with license restrictions. At time of writing, the most recent public release was WW3 version 4.18 (Tolman et al., 2014).

During the first decade of this century, WW3 evolved from a code written exclusively by a single author into a 
community effort. This is comparable to the community efforts around development of WAM (WAMDI Group, 1988) in the late 1980s and early 1990s, culminating in WAM Cycle 4 (Komen et al., 1994) ${ }^{1}$ and SWAN (Simulating WAves Nearshore; Booij et al., 1999) improvement efforts in the late 1990s and early the model (WW3 version 4) is able to optionally represent a number of other source terms, including the effects of bottom friction, bottom scattering, sea ice, reflection from icebergs and steep shorelines, surf breaking, fluidized mud, and three-wave (triad) nonlinear interactions. In some cases, multiple options

THE FNMOC OPERATIONAL SYSTEM IS DESIGNED WITH TWO PRIORITIES IN MIND: (1) RAPID DEPLOYMENT OF THE GLOBAL PRODUCT, AND (2) EXPLOITATION OF HIGH-RESOLUTION METEOROLOGICAL PRODUCTS.

2000s. A key enabler for the move toward a community-managed model has been a National Ocean Partnership Program (NOPP) for wave physics (Tolman et al., 2013), funded primarily by the Office of Naval Research and NOAA. The latter provides the version-control infrastructure required for simultaneous development of the same code by numerous authors, including personnel from NOAA, Ifremer (France), US Navy, UK Met Office, Swinburne University (Australia), and others.

\section{General Features}

The governing equation of WW3 is a variant of the action balance equation given in Equation 1 above. In addition to the three traditional deepwater source functions mentioned in the paper's first section, the latest version of exist for the same physical process, allowing different theories, parameterizations, and numerical rigor. In addition to static bathymetry, the model optionally ingests several fields that may be non-stationary and non-uniform: surface currents, water levels, ice characteristics, 10-meter wind vectors, and airsea temperature differences (the last for representation of atmospheric stability). Unresolved islands and ice can be treated with subgrid parameterization. In public release version 3 , the multigrid or mosaic approach of Tolman (2008) was introduced. In this approach, nesting is performed using internal communications, and all grids are run within a single executable program rather than the old approach of executing a sequence of programs, one for each grid, communicating via files containing directional spectra.
The new approach allows for two-way nesting, exchanging spectra between domains. For example, energy generated in a high-resolution WW3 grid may be propagated out to the lower-resolution global WW3 grid as swell, and then back to another high resolution WW3 grid on the other side of the ocean.

Where WW3 version 3 only allowed regular structured grids, WW3 version 4 can perform computations on irregular structured and unstructured grids. Propagation schemes of first-, second-, and third-order accuracy can be selected according to a user's preferences of accuracy vs. computational cost. Output has also been extended to include NetCDF format. Many new variables are added to output, such as momentum flux variables relevant to coupling with atmospheric and ocean models, and wave-breaking statistics such as whitecap coverage. On multiple processors, WW3 can use distributed memory parallelism via Message Passing Interface (MPI), with domain decomposition over both geographic and spectral grids during separate time steps for source term calculation and geographic propagation.

One especially noteworthy development is the introduction of the new generation of more physically realistic deepwater dissipation functions in the model by Ardhuin et al. (2010) and Zieger et al. (2011). The latter model is part of a source term package that is essentially identical to the new deepwater physics installed in SWAN by NRL (see Allard et al., 2014, in this issue). Thus, it is possible to use consistent physics between WW3 and SWAN, thereby reducing discontinuities at WW3-to-SWAN nesting boundaries (discussed later in

'An evolved version of WAM, known as ECWAM (Bidlot, 2012), employed at the European Centre for Medium-Range Weather Forecasts, has undergone significant code modernization relative to WAM4. In some cases, features similar to those described herein have been added for WW3, albeit with a slightly different approach. 
the section on WAVEWATCH III at NAVOCEANO). Previously, this manner of consistency was possible only by using a very crude variety of source functions in both models.

\section{WAVEWATCH III AT FNMOC}

FNMOC is the Navy operational center with primary responsibility for global and large regional-scale wave models. In August 2001, FNMOC replaced WAM with WAVEWATCH III, motivated by a change in computer architecture necessitating adoption of MPI methods for parallel processing (Wittmann, 2002), the open source policy of WW3, and WW3's accurate propagation scheme that makes it possible to distinguish separate swell systems in time series of nondirectional spectra (Wingeart et al., 2001).

The FNMOC operational system is designed with two priorities in mind: (1) rapid deployment of the global product, and (2) exploitation of high-resolution meteorological products. The first priority implies that the global wave product should be available very soon after the global meteorological product is available, and contrasts with the priorities of the Naval Oceanographic Office (NAVOCEANO; see below). This priority discourages use of the multigrid feature of WW3, which requires that all grids run at once, and so no output is available until the entire system is complete. The second priority implies that regional grids are designed to coincide with regional meteorological models, which are implementations of the Coupled Ocean/Atmospheric Mesoscale Prediction System (COAMPS; Hodur, 1997). This priority contrasts with the approach of NCEP, in which regional models are most often forced by the National Weather Service's Global Forecasting System (GFS). Since
February 2013, the global WW3 at FNMOC is forced by the NAVy Global Environmental Model (NAVGEM; Hogan et al., 2014, in this issue). At present, the WW3 grids used at FNMOC are all regular grids. Routine inputs are as follows:

1. $10 \mathrm{~m}$ wind vectors and air-sea temperature differences (used to account for the effect of atmospheric stability on air-sea momentum flux) are ingested from a meteorological model

2. Bathymetry and subgrid scale obstruction grids are generated using auxiliary software, which uses a 2 ' resolution database for bathymetry (ETOPO2)

3. Ice concentration is taken from SSMI (Special Sensor Microwave Imager) reanalysis, and the continuous treatment of ice, as in Tolman (2003), is used
The global model is run to 180 hours, and the regional models forecast to varying lengths, from 36 to 96 hours. Figure 1 shows the grids included in the FNMOC operational system at time of writing. With the stand-alone WW3 systems such as shown in this figure, wave feedback to the atmosphere (modified surface roughness) is not considered, and coupling with an ocean model is not performed.

WW3 has also been integrated into the COAMPS On-Scene (COAMPS-OS) system (Geiszler et al., 2004). The COAMPS-OS system is a modeling interface that allows for rapid implementation of new areas to meet urgent requests for high-resolution wind and wave forecasts. Though not yet operational, it also provides a framework to fully couple atmospheric, ocean, and wave models. Eventually, all the regional

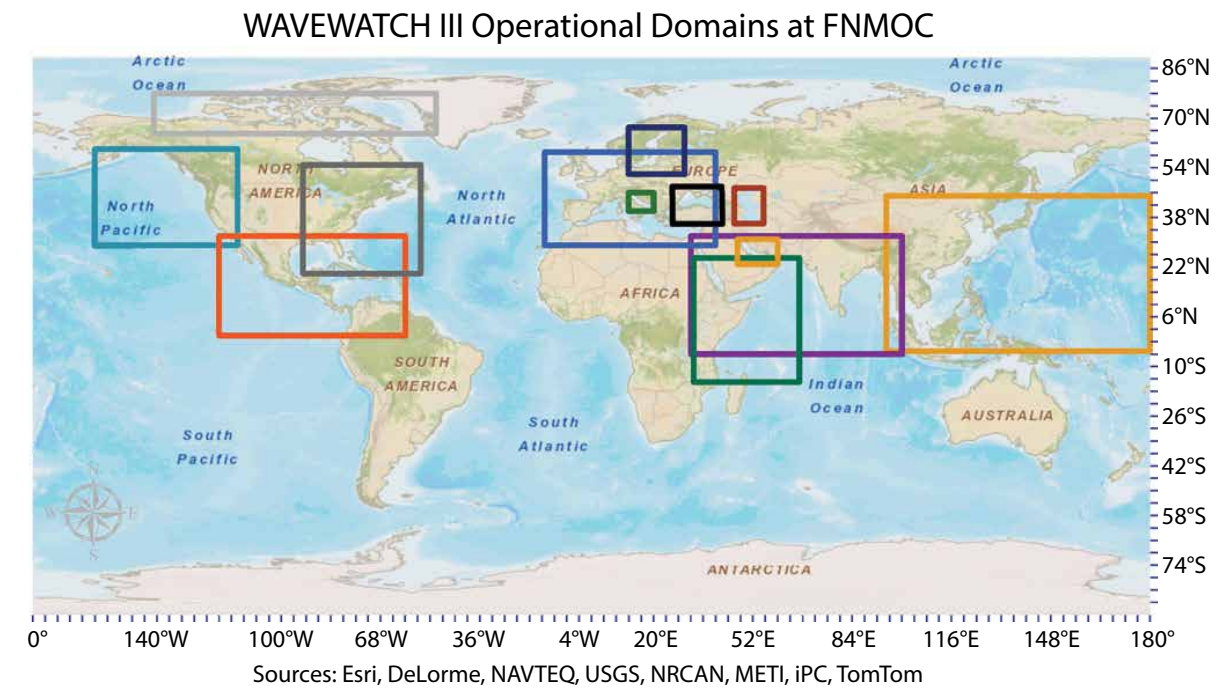

REGIONAL DOMAINS

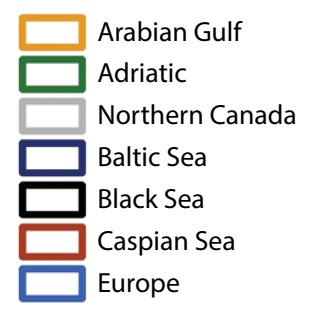

Figure 1. FNMOC WAVEWATCH III (WW3) regional domains. Larger grids are $0.2^{\circ}$ resolution, and some are finer, $0.1^{\circ}$. Most grids correspond to Coupled Ocean/Atmospheric Mesoscale Prediction System (COAMPS) domains. 
WW3 implementations will be running under the COAMPS-OS infrastructure.

Assimilation of wave height measurements from satellite altimeters was added to the FNMOC global WW3 model in November 2004 (Wittmann and Cummings, 2004). In March 2011, moored buoy wave height measurements were added to the wave data assimilation. The maximum benefit of wave data assimilation is seen during the early forecast time. After approximately 96 hours, the corrections to the initial wave height field are overwhelmed by the wind forcing and dispersion effects. In October 2012, the assimilation was upgraded from a simple optimum interpolation (OI) to a three-dimensional variational (3DVAR) scheme (Smith et al., 2011). At the time of writing, data are used from three satellite altimeters: CryoSat, ALtiKa, and Jason-2.

WW3 computes a directional wave spectrum at each grid point. The model routinely outputs wave parameters derived from the wave spectra, such as significant wave height, peak wave period, peak wave direction, usually at three-hour time intervals throughout the forecast (e.g., Figure 2). The model also outputs the full spectra at selected points, such as buoy locations, for model verification. With the implementation of WW3 version 3.14, the model also decomposes the spectra into wave systems, such as wind sea, primary swell, and secondary swell. At FNMOC, these partitioned parameters are used in a Web application, WaveVIS, which allows the user to get a point forecast of wave systems.

FNMOC has been running a 20-member WW3 global ensemble since 2003. The ensemble members are run on a global 1 degree $(\sim 110 \mathrm{~km})$ resolution grid to 240 hours, and are forced by the

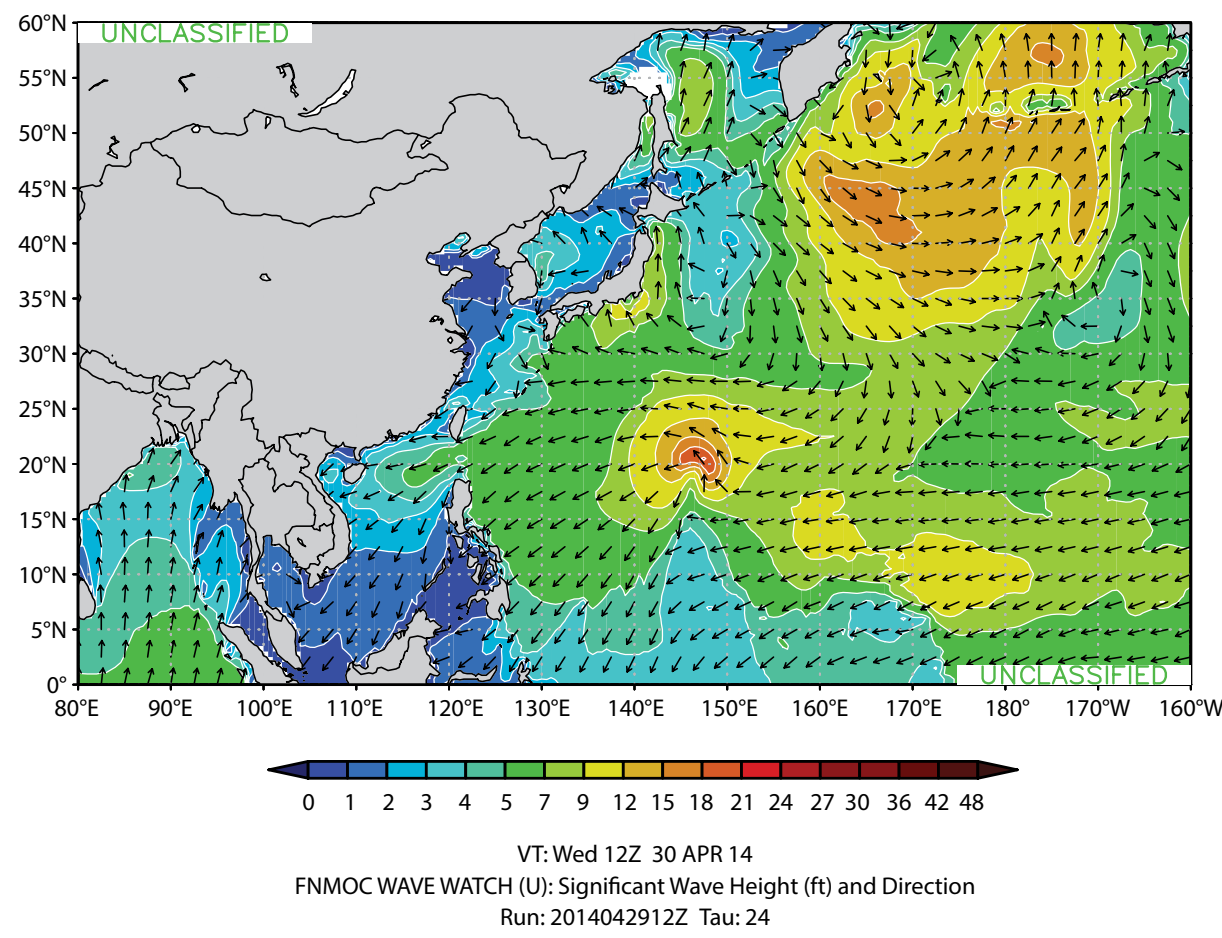

Figure 2. Significant wave height in feet (indicated with color scaling) and mean direction (indicated with arrows) for the 24-hour forecast for October 23, 2013, 00 GMT, from the WW3 West Pacific regional model forced by COAMPS winds.
FNMOC NAVGEM ensemble, which provides the variability through wind forcing. In 2011, the FNMOC WW3 ensemble was combined with the NCEP 21-member WW3 ensemble, creating a 41-member wave ensemble (Alves et al., 2013). Future plans call for increasing the resolution to 0.5 degree, upgrading to WW3 version 4, and including the 20-member WW3 ensemble from Environment Canada.

FNMOC and NRL-Monterey have developed a tropical cyclone wave forecasting system using the Automated Tropical Cyclone Forecasting (ATCF) system and WW3 (Sampson et al., 2010). ATCF provides the official tropical cyclone track and intensity forecast, which is derived from a consensus of NWP model and forecaster input, with the latter typically provided by the Joint Typhoon Warning Center (JTWC). Wind grids are then created from the official track and used to force high-resolution WW3 implementation. This tropical cyclone wave forecast can be important in making decisions to sortie ships ahead of an approaching tropical storm. Figure 3 shows an example from a 120-hour forecast of WP152009 (Typhoon Choi-Wan) from September 14, 2009, at 1200 UTC. The shaded field is Navy Operational Global Atmospheric Prediction System (NOGAPS)/WW3 and the contoured field is JTWC/WW3; a significant discrepancy in storm position between these two products is evident. This new product (JTWC/WW3) produces a wave forecast that is consistent with the official tropical forecast (JTWC). The first green shade indicates area of significant wave heights $>12 \mathrm{ft}(\sim 4 \mathrm{~m})$, which is the key value for US Navy maritime operations. Black and orange tracks are the past positions and the JTWC forecasts, respectively. 


\section{WAVEWATCH III AT}

\section{NAVOCEANO}

In contrast to the priorities at FNMOC, the primary focus at NAVOCEANO is to provide support for planning and operation missions concentrating on littoral waters, which require small-scale high-resolution forecasts, typically using the nearshore wave model SWAN. These small domains (of which there can be many) require boundary conditions ultimately provided by the global system. Since the early 1990s, WAM was the wave model used at NAVOCEANO to provide global and large-scale predictions. As the demand for accurate wave forecasts of littoral regions increased, this model was adapted for quick setup of small relocatable domains. The requests for new prediction areas arriving at NAVOCEANO were so numerous that it was impractical to request support from FNMOC, motivating a locally run global system at NAVOCEANO for wave boundary conditions.

For a number of years following the adoption of WW3 at FNMOC, WAM persisted at NAVOCEANO, adapted to run on continually evolving and faster high performance machines at the thennamed Department of Defense (DoD) Major Shared Resource Center. These architectures proved suitable for quick turnaround of WAM operated in serial mode with relatively few sea points per grid. During the prior decade (2000s), evaluations such as those of Wittmann (2002) and Rogers (2002) indicated that the benefit of moving from WAM4 to WW3 with respect to simple metrics of accuracy (e.g., wave height RMSE) would be small. However, by the present decade, rapid technological advancement with the WW3 code (see earlier discussion) and its "community development" approach was sufficient to convince
NRL to favor movement to WW3. This coincided with increasing pressure from the parent organization of FNMOC and NAVOCEANO (Commander, Naval Meteorology and Oceanography Command) for the two centers to use a consistent modeling code.

The multigrid WW3 version 4 was implemented in a real-time system on the DoD Supercomputer Resource Center (DSRC) and validated (Rogers et al., 2012), satisfying the first major condition for transition to NAVOCEANO, which is now running a similar parallel system for operational testing, also on the DSRC. With this semiredundant approach, NRL personnel can test experimental features and new grids on their real-time system, as personnel at NAVOCEANO independently maintain their more stable real-time system.

Relative to the previous WAM implementations, individual WW3 grids are implemented on fewer grids with a much larger number of sea points per grid, which is made possible by using distributed parallel computing (MPI). Figure 4 shows a layout of domains for a currently tested system. At the time of writing, all domains shown are operational on the DSRC, except for the Arctic and Australia domains, which are currently being tested in the pre-operational developmental system on the DSRC. The global domain is grid spaced at 0.5 degrees, while the regional domains are 0.1 or 0.2 degrees, except the Arctic curvilinear grid, which is at $16 \mathrm{~km}$. Although the global component of the multigrid system completes later than it would if run independently (as at FNMOC), this configuration maximizes the benefit derived from the superior winds of the higher-resolution regional COAMPS implementations via the two-way nesting: waves generated in a regional grid can affect swell predictions at remote coastlines.

FNMOC provides the wind fields. For the global domain, NAVGEM is provided at 0.5 degree grid spacing, and for regional domains, COAMPS is typically at 0.2 degree grid spacing. Most

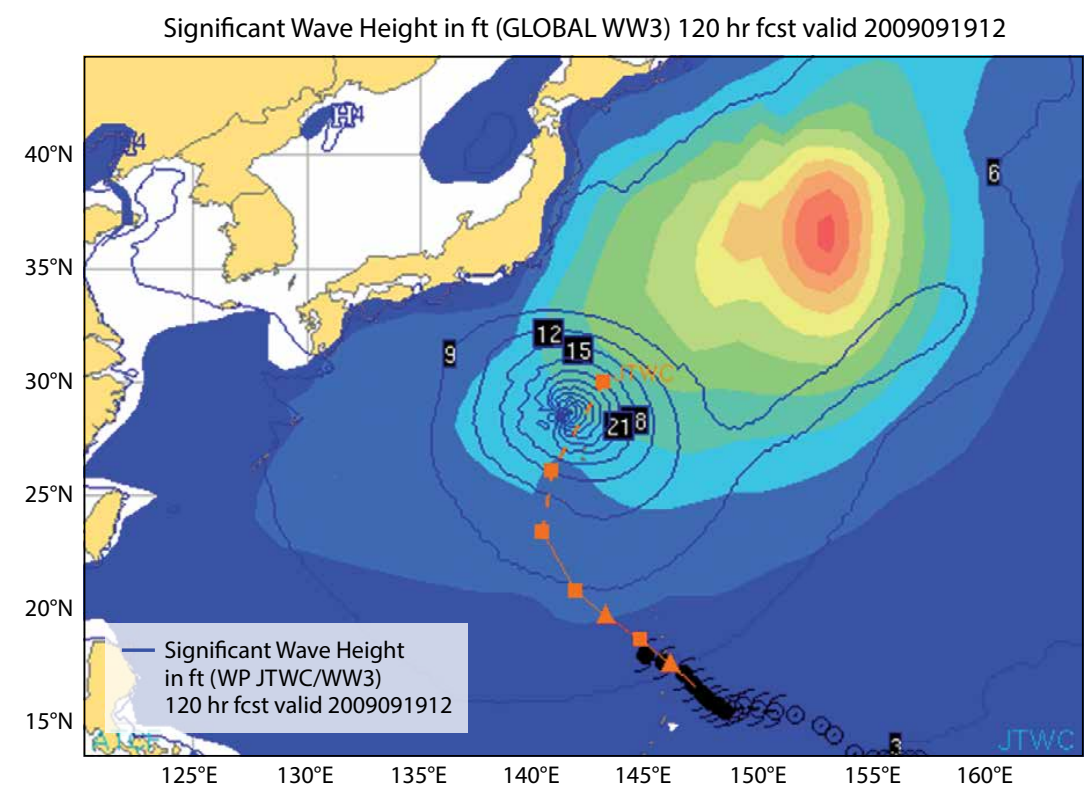

Figure 3. Forecast example of differences in geographical location of significant wave heights associated with tropical cyclones. See text for description. Credit: C. Sampson (NRL) 
WAVEWATCH III Operational Domains at NAVOCEANO

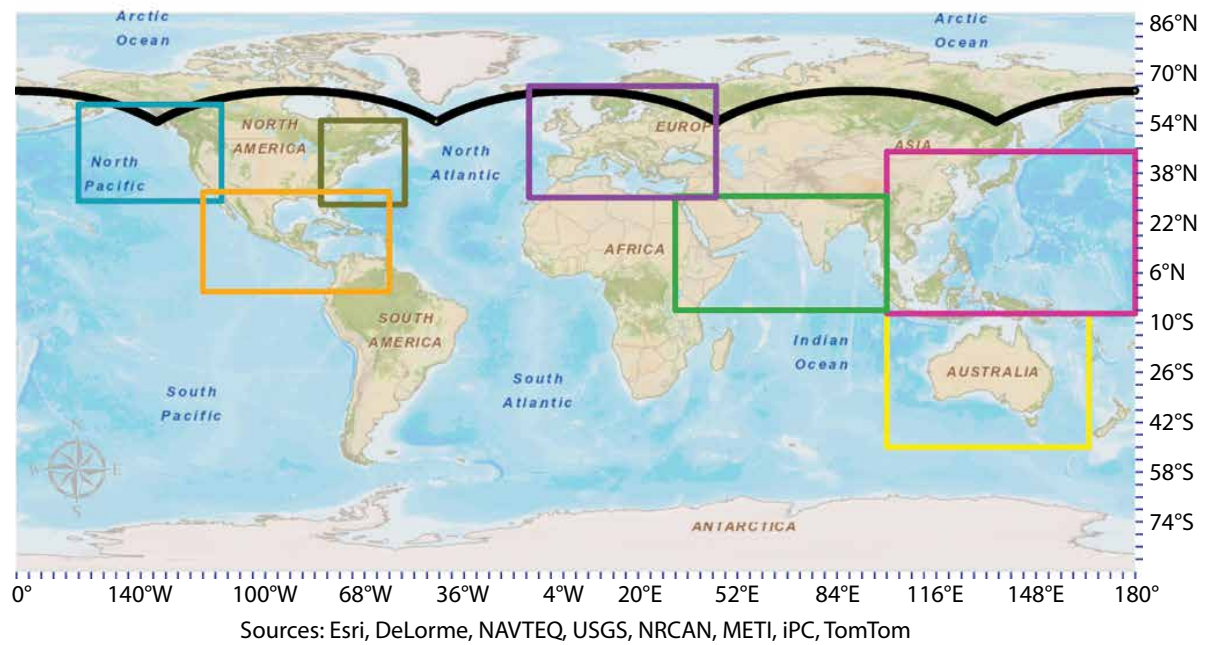

REGIONAL DOMAINS

Central America

Europe

Northeastern Pacific

Northern Indian Ocean

Northwestern Atlantic

Northwestern Pacific

Australia

- Arctic

\section{SWAN Domains Nested in WAVEWATCH III Domain}

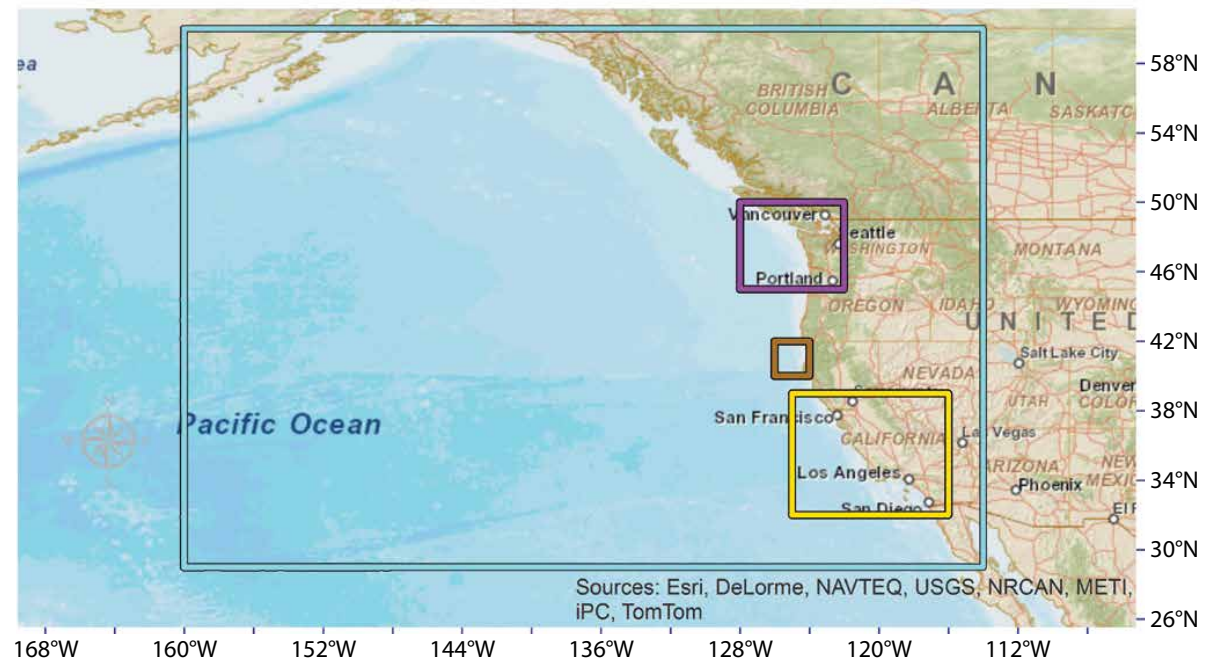

MODEL DOMAINS

WW3 Region Host

SWAN Region 2

SWAN Region 3

SWAN Region 4
Figure 4. Layout of the regional domains for the multigrid system running at the Naval Oceanographic Office (NAVOCEANO). The Northeastern Pacific grid is also shown in Figure 5.

of the regional WW3 domains roughly coincide with COAMPS domains.

A somewhat unique feature of NAVOCEANO wave forecasting is the large and ever-changing number of required forecast locations throughout the globe. WW3 delivers boundary conditions in packages marked for each nested wave modeling domain, for which a coastal model is run. Figure 5 depicts an example of wave model domains nested within the WW3 domain covering the northeastern Pacific Ocean. Within any of these domains, additional levels of coastal and nearshore subnests (typically SWAN) may be set up, transparent to WW3, which interacts only with the first-level nest. As of November 1, 2013, there were 357 unclassified SWAN implementations running at NAVOCEANO, primarily for subregional (e.g., shelf-scale) domains.

The NAVOCEANO wave modeling system offers additional products based on directional spectra saved at all grid points at three hourly intervals throughout the forecast period. Just as the normally available bulk parameters such as significant wave height and mean wave direction are calculated from these spectra internal to WW3, algorithms for additional parameters have been developed and can be output along with the traditional results via post-processing. These additional parameters include length-scale dependent mean-squared slope, used as to quantify steepness appropriate for five different vessel sizes; a "crossing sea" metric that provides locations where significant wave energy is predicted to be approaching from multiple directions (a sea-keeping hazard); maps of sea and swell wave height; and local swell system analysis that depicts a time series of swell and wind waves based on partitions output provided by 
the model at a user-specified location.

Figure 6 illustrates a sample crossing seas product for the globe. This image is from the nowcast (TAU 00) taken from a run cycle initialized at 06 August 2013 UTC. The calculation is based on unpublished methods provided by Uriah Gravois

(University of Florida).

The NAVOCEANO WW3 system is in the early stages, and a number of key shortcomings have been identified for future improvement. The multigrid system presently forecasts out to 48 hours, corresponding to the shortest available forecast from the COAMPS domains. Ice coverage is specified as a static placeholder field. Wave-ocean coupling is not implemented. Unlike FNMOC, no data assimilation is performed for waves at NAVOCEANO, and there is no consideration of air-sea temperature differences (for stability effects) in the forcing fields.

\section{NEXT STEPS: CAPABILITIES FORTHCOMING}

During the next two years, NRL will add new grids to the experimental real-time system operated by NRL on the DSRC, and NAVOCEANO will evaluate these grids to determine whether they can be incorporated into the official operational system. As mentioned above, the primary determination of existing regional grids is the availability of COAMPS regional atmospheric model output for a region. Because these COAMPS implementations are by now suitably exploited by the regional WW3 grids, other determinations will be used for the new grids. One example is a polar stereographic (curvilinear) Arctic grid, which is being tested now on the DSRC. The primary motivation for this grid is to avoid the narrowing of grid cells that occurs in the regular grid at high latitudes. Another example is the Australia grid, included in Figure 4, also being tested on the DSRC. In this case, the grid is designed as a so-called "coastal grid" using methods described in Tolman (2008). In this paradigm, the grids are still regular, but sea points far from the coast are masked (i.e., not treated as computational grid points); these geographic locations are instead represented in the global model at coarser resolution. The grid boundaries in such a setup are essentially coastline following. This is a simple method for applying high resolution where it is most needed. Additional grids will be added in calendar year 2014, targeting the coastal regions still treated now at the resolution of the global WW3 grid $\left(0.5^{\circ}\right)$, primarily around South America and Africa.

The Earth System Prediction Capability project is a new effort primarily concerned with the implementation and testing of global coupled modeling systems. The atmosphere-ocean-wave coupling methods will follow those established for regional models (COAMPS, see Allard et al., 2014, in this issue), but there will be new, focused efforts in both systems to implement more system-wide consistency in momentum fluxes. For example, the momentum lost to the atmosphere at the air-ocean interface should equal the sum of the momentum gained on the water side, partitioned between the waves (normal stress) and the mean flow (tangential stress). Two motivations for high-resolution wave modeling have already been mentioned above: to exploit high-resolution winds and to represent coastal regions with higher resolution. The global coupling introduces a third motivation for high resolution. With wave-ocean coupling, high resolution is required everywhere (globally) to represent the effects of eddies and similar features on surface waves. The working plan is to implement a $1 / 8^{\circ}$ WW3 coupled with a $1 / 25^{\circ} \mathrm{HYCOM}$. However, a grid with this many sea points (over $2 \times 10^{6}$ ) presents a number

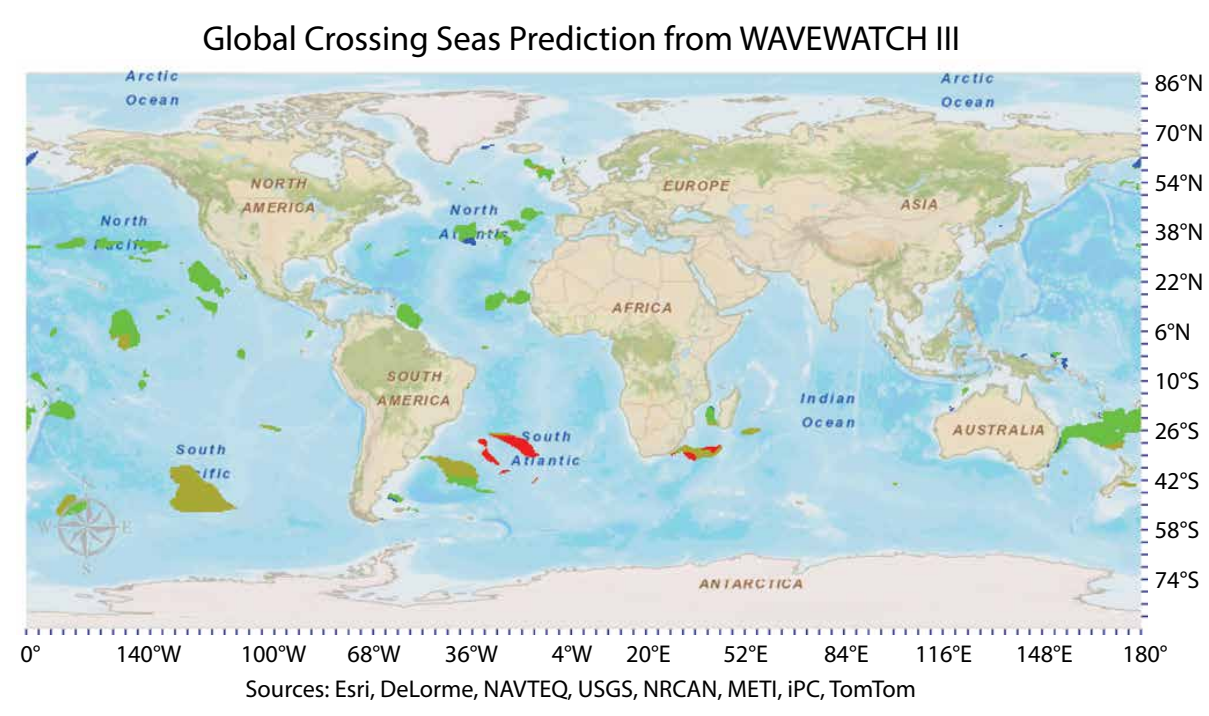

$\begin{array}{ll}\text { CROSSING SEAS }(\mathrm{m}) & \text { Figure 6. Plot of sample results of the crossing seas algorithm for the } \\ \leq 1 & \text { entire global system including the regional domains. The values are } \\ \text { divided into four groupings of significant wave height (in meters) } \\ 1-2 & \text { where crossing seas are predicted, with larger numbers indicating } \\ 2-3 & \text { greater seakeeping hazard. See text for further description. } \\ >3 & \end{array}$ 
of significant technical challenges, which are being addressed with ongoing code development efforts.

\section{ACKNOWLEDGEMENTS}

A number of scientists and software developers have made important contributions to the wave modeling efforts described here. The authors thank Dan Geiszler (FNMOC applications), Jim Cummings (FNMOC data assimilation), Rick Allard (coupled modeling), David Wang (swell analysis), Buck Sampson (consistent tropical forecasts), Arun Chawla (grid generation software), Uriah Gravois (new output parameters, e.g., crossing seas prediction), Tim Campbell (grid methods, scripting and code maintenance), Stefan Zieger, and the WW3 development team. We thank Jeikook Choi (NAVOCEANO), Jean Bidlot (European Centre for Medium-Range Weather Forecasts, ECMWF), Charles Cox, and two anonymous reviewers for useful recommendations. This work is funded in part by the Office of Naval Research through the National Oceanographic Partnership Program under program element $0602435 \mathrm{~N}$ and by the Space and Naval Warfare Systems Command under program element $0603207 \mathrm{~N}$. This paper is contribution NRL/JA/732014-2099 and has been approved for public release.

\section{REFERENCES}

AIP. 1986. Interview of W. Munk by F. Aeserud on June 30, 1986. Niels Bohr Library \& Archives, American Institute of Physics, College Park, MD USA, http://www.aip.org/history/ ohilist/4790.html.

Allard, R., E. Rogers, P. Martin, T. Jensen, P. Chu, T. Campbell, J. Dykes, T. Smith, J. Choi, and U. Gravois. 2014. The US Navy coupled ocean-wave prediction system. Oceanography 27(3):92-103, http://dx.doi.org/ 10.5670/oceanog.2014.71.
Alves, J.-H.G.M., P. Wittmann, M. Sestak, J. Schauer, S. Stripling, N.B. Bernier, J. McLean, Y. Chao, A. Chawla, H. Tolman, and others. 2013. The NCEP/FNMOC Combined Wave Ensemble Product: Expanding benefits of inter-agency probabilistic forecasts to the oceanic environment. Bulletin of the American Meteorological Society 94:1,893-1,905, http://dx.doi.org/10.1175/BAMS-D-12-00032.1. Ardhuin, F., E. Rogers, A.V. Babanin, J.-F. Filipot, R. Magne, A. Roland, A. van der Westhuysen, P. Queffeulou, J.-M. Lefevre, L. Aouf, and F. Collard. 2010. Semiempirical dissipation source functions for ocean waves. Part I: Definition, calibration, and validation. Journal of Physical Oceanography 40:1,917-1,941, http://dx.doi.org/10.1175/2010JPO4324.1.

Bidlot, J.-R. 2012. Present status of wave forecasting at ECMWF. Paper presented at the ECMWF Workshop on Ocean Waves, June 25-27, 2012. European Centre for Medium-Range Weather Forecasts, Reading, United Kingdom.

Booij, N., R.C. Ris, and L.H. Holthuijsen. 1999. A third-generation wave model for coastal regions: Part 1. Model description and validation. Journal of Geophysical Research 104(C4):7,649-7,666, http://dx.doi.org/10.1029/98JC02622.

Cavaleri, L., J.-H.G.M. Alves, F. Ardhuin, A. Babanin, M. Banner, K. Belibassakis, M. Benoit, M. Donelan, J. Groeneweg, T.H.C. Herbers, and others. 2007. Wave modelling: The state of the art. Progress in Oceanography 75:603-674, http://dx.doi.org/ 10.1016/j.pocean.2007.05.005.

Clancy, R.M., J.E. Kaitala, and L.F. Zambresky. 1986. The Fleet Numerical Oceanography Center Global Spectral Ocean Wave Model. Bulletin of the American Meteorological Society 67:498-512, http://dx.doi.org/10.1175/ 1520-0477(1986)067<0498:TFNOCG> 2.0.CO;2.

Durrant, T.H., D.J.M. Greenslade, and I. Simmonds. 2013. The effect of statistical wind corrections on global wave forecasts. Ocean Modelling 70:116-131, http://dx.doi.org/ 10.1016/j.ocemod.2012.10.006.

Geiszler, D.A., J. Kent, J.L.S. Strahl, J. Cook, G. Love, L. Phegley, J. Schmidt, Q. Zhao, F. Franco, L. Frost, and others. 2004. The Navy's on-scene weather prediction system. Paper presented at COAMPS-OS, $20^{\text {th }}$ Conference on Weather Analysis and Forecasting/ $16^{\text {th }}$ Conference on Numerical Weather Prediction. American Meteorological Society.

Gelci, R., H. Cazale, and J. Vassal. 1956. Utilisation des diagrammes de propagation a la prevision energetique de la houle. Bulletin d'information du Comite d'Oceanographie et d'Etude des Cotes 8(4):160-197.

Hasselmann, K. 1960. Grundgleichungen der Seegangsvoraussage. Schiffstechnik 7(39):191-195.
Hodur, R.M. 1997. The Naval Research Laboratory's Coupled Ocean/Atmospheric Mesoscale Prediction System (COAMPS). Monthly Weather Review 125:1,414-1,430, http://dx.doi.org/10.1175/1520-0493(1997)125 $<1414$ :TNRLSC>2.0.CO;2.

Hogan, T.F., M. Liu, J.A. Ridout, M.S. Peng, T.R. Whitcomb, B.C. Ruston, C.A. Reynolds, S.D. Eckermann, J.R. Moskaitis, N.L. Baker, and others. 2014. The Navy Global Environmental Model. Oceanography 27(3):116-125, http://dx.doi.org/10.5670/oceanog.2014.73.

Hubert, W.E. 1957. A preliminary report on numerical sea condition forecasts. Monthly Weather Review 85:200-204, http://dx.doi.org/ 10.1175/1520-0493(1957)085<0200:APRONS> 2.0.CO;2.

Jensen, R.E., P.A. Wittmann, and J.D. Dykes. 2002. Global and regional wave modeling activities. Oceanography 15(1):57-66, http://dx.doi.org/ 10.5670/oceanog.2002.36.

Kinsman, B. 1984. Wind Waves: Their Generation and Propagation on the Ocean Surface. Dover, $676 \mathrm{pp}$.

Komen, G.J., L. Cavaleri, M. Donelan, K. Hasselmann, S. Hasselmann, and P.A.E.M. Janssen. 1994. Dynamics and Modelling of Ocean Waves. Cambridge University Press, 532 pp.

Munk, W., and D. Day. 2002. Harald U. Sverdrup and the war years. Oceanography 15(4):7-29, http://dx.doi.org/10.5670/oceanog.2002.02.

O’Reilly, W.C., and R.T. Guza. 1993. A comparison of two spectral wave models in the Southern California Bight. Coastal Engineering 19:263-282, http://dx.doi.org/ 10.1016/0378-3839(93)90032-4.

Rogers, W.E. 2002. The US Navy's Global WindWave Models: An Investigation into Sources of Error in Low Frequency Energy Predictions. NRL Formal Report 7320-02-10035, 63 pp., http://www7320.nrlssc.navy.mil/pubs/2002/ rogers_FR2002.pdf.

Rogers, W.E., P.A. Wittmann, D.W. Wang, R.M. Clancy, and Y.L. Hsu. 2005. Evaluations of global wave prediction at the Fleet Numerical Meteorology and Oceanography Center. Weather Forecasting 20:745-760, http://dx.doi.org/10.1175/WAF882.1.

Rogers, W.E., J.D. Dykes, D. Wang, S.N. Carroll, and K. Watson. 2012. Validation Test Report for WAVEWATCH III. NRL Memorandum Report 7320-12-9425, 75 pp.

Sampson, C.R., P.A. Wittmann, and H.L. Tolman. 2010. Consistent tropical cyclone wind and wave forecasts for the US Navy. Weather Forecasting 25:1,293-1,306, http://dx.doi.org/ 10.1175/2010WAF2222376.1.

Smith, S., J.A. Cummings, C. Rowley, P. Chu, J. Shriver, R. Helber, P. Spence, S. Carroll, O.M. Smedstad, and B. Lunde. 2011. Validation Test Report for the Navy Coupled Ocean Data Assimilation 3D Variational Analysis 
(NCODA-VAR) System, Version 3.43. NRL Report NRL/MR/7320-11-9363, Naval Research Laboratory, Stennis Space Center, MS, 135 pp.

Su, M.-Y., and C.L. Vincent. 1996. Developing a Joint Army/Navy Coastal Wave Prediction Program. Naval Research Laboratory Memorandum Report NRL/MR/7330-95-7686, $97 \mathrm{pp}$.

Tolman, H.L. 1991. A third-generation model for wind-waves on slowly varying, unsteady, and inhomogeneous depths and currents. Journal of Physical Oceanography 21:782-797, http://dx.doi.org/10.1175/1520-0485(1991)021 $<0782$ :ATGMFW>2.0.CO;2.

Tolman, H.L. 2003. Treatment of unresolved islands and ice in wind wave models. Ocean Modelling 5:219-231, http://dx.doi.org/10.1016/ S1463-5003(02)00040-9.

Tolman, H.L. 2008. A mosaic approach to wind wave modeling. Ocean Modelling 25:35-47, http://dx.doi.org/ 10.1016/j.ocemod.2008.06.005.

Tolman, H.L., and the WAVEWATCH III ${ }^{\circ}$ Development Group. 2014. User Manual and System Documentation of WAVEWATCH III ${ }^{\circ}$ version 4.18. Technical Note 316, NOAA/NWS/ NCEP/MMAB, 282 pp. + Appendices.

Tolman, H.L., B. Balasubramaniyan, L.D. Burroughs, D.V. Chalikov, Y.Y. Chao, H.S. Chen, and V.M. Gerald. 2002. Development and implementation of wind-generated ocean surface wave models at NCEP. Weather and Forecasting (NCEP Notes) 17:311-333, http://polar.ncep. noaa.gov/mmab/papers/tn208/OMB208.pdf.

Tolman, H.L., M.L. Banner, and J.M. Kaihatu. 2013. The NOPP operational wave model improvement project. Ocean Modelling 70:2-10, http:// dx.doi.org/10.1016/j.ocemod.2012.11.011.

WAMDI Group. 1988. The WAM model: A third generation ocean wave prediction model. Journal of Physical Oceanography 18:1,775-1,810, http://dx.doi.org/ 10.1175/1520-0485(1988)018<1775: TWMTGO $>2.0 . \mathrm{CO} ; 2$.

Wingeart, K.M., T.H.C. Herbers, W.C. O'Reilly, P.A. Wittmann, R.E. Jensen, and H.L. Tolman. 2001. Validation of operational global wave prediction models with spectral buoy data. Proceedings of the Fourth International Symposium; Ocean Wave Measurement and Analysis ("WAVES 2001"). San Francisco, CA, ASCE, 590-599, http://dx.doi.org/10.1061/ 40604(273)61.

Wittmann, P.A. 2002. Implementation of WaveWatch III at Fleet Numerical Meteorology and Oceanography Center. Pp. 1,474-1,479 in vol. 3 of OCEANS, 2001: MTS/IEEE Conference and Exposition, http://dx.doi.org/10.1109/ OCEANS.2001.968051.

Wittmann, P.A., and R.M. Clancy. 1993. Implementation and validation of a global third-generation wave model at Fleet Numerical Oceanography Center. Pp. 406-419 in
Proceedings of the $2^{\text {nd }}$ International Symposium on Ocean Wave Measurement and Analysis, New Orleans, Louisiana.

Wittmann, P.A., and M. Clancy. 2004. Thirty years of operational ocean wave forecasting at Fleet Numerical Meteorology and Oceanography Center. Paper presented at the Symposium on the 50th Anniversary of Operational Numerical Weather Prediction, June 14-17, 2004, University of Maryland, $6 \mathrm{pp}$.

Wittmann, P.A., and J.A. Cummings. 2004. Assimilation of altimeter wave measurements into WAVEWATCH III. Paper presented at the $8^{\text {th }}$ International Workshop on Wave Hindcasting and Forecasting, North Shore, Oahu, Hawaii, November 14-19, 2004.

Wittmann, P.A., R.M. Clancy, and T. Mettlach. 1995. Operational wave forecasting at Fleet Numerical Meteorology and Oceanography Center. Pp. 335-342 in Proceedings of the $4^{\text {th }}$ International Workshop on Wave Hindcasting and Forecasting. Banff, Alberta, Canada.

Zieger, S., A.V. Babanin, W.E. Rogers, and I.R. Young. 2011. Observation-based dissipation and input terms for WAVEWATCH III ${ }^{\mathrm{TM}}$ : Implementation and simple simulations. Proceedings of the $12^{\text {th }}$ International Workshop on Wave Hindcasting and Forecasting. Kohala Coast, HI, October 30-November 4, JCOMM Technical Report No. 67, 12 pp., http://www.jcomm.info/images/stories/2011/ 12thWaves/Papers/ziegeretal_2011.pdf. 